PressAcademia Procedia

YEAR 2018 VOLUME 7

4th Global Business Research Congress, May 24-25, 2018, Istanbul, Turkey.

\title{
EFFICIENCY MEASUREMENT AT AIRLINE CITY-PAIR MARKETS WITH DATA ENVELOPMENT ANALYSIS AND MALMQUIST PRODUCTIVITY INDEX
}

\author{
DOI: 10.17261/Pressacademia.2018.886 \\ PAP- V.7-2018(39)-p.228-232
}

\section{Mehmet Yasar', Veysi Asker², Emircan Ozdemir ${ }^{3}$}

${ }^{1}$ Anadolu University, Faculty of Aeronautics and Astronautics, Eskisehir, Turkey. mehmet_yasar@anadolu.edu.tr, ORCID: 0000-0001-7237-4069

${ }^{2}$ Anadolu University, Faculty of Aeronautics and Astronautics, Eskisehir, Turkey. veysiasker@anadolu.edu.tr, ORCID: 0000-0002-8969-7822

${ }^{3}$ Anadolu University, Faculty of Aeronautics and Astronautics, Eskisehir, Turkey. emircanozdemir@anadolu.edu.tr, ORCID: 0000-0002-1383-4712

To cite this document

Yasar, M., Asker, V., Ozdemir, E. (2018). Efficiency measurement at city-pair markets with data envelopment analysis and Malmquist productivity index. PressAcademia Procedia (PAP), V.7, p.228-232.

Permemant link to this document: http://doi.org/10.17261/Pressacademia.2018.886

Copyright: Published by PressAcademia and limited licenced re-use rights only.

\section{ABSTRACT}

Purpose- The aim of this study is to reveal the efficiency ratings of airline city pairs markets. In this context, data envelopment analysis and Malmquist Total Factor Efficiency Indexes are used for efficiency measurement.

Methodology- The biggest 16 city-pair markets in terms of the passengers revenue traffic were included in the analysis between the years 2015-2017. Passengers revenue traffic and load factor as output variables under analysis; variables such as the number of available seats, the number of flights were used as input variables.

Findings- According to the results of the data envelopment analysis, Athens, Newyork, Berlin and Tehran markets are effective and others are not effective.

Conclusion- According to the results of the total factor productivity index, it is seen that THY has increased its effectiveness in Tel Aviv, Frankfurt and Stuttgart markets. The findings of this study are thought to lead to stakeholders in the airline sector.

Keywords: Data envelopment analysis, total factor productivity index, efficiency measurement, city-pair markets, airlines.

JEL Codes: C80, L91, L93

\section{HAVAYOLU ŞEHIR ÇIFTi PAZARLARINDA VERI ZARFLAMA ANALIZi VE MALMQUIST TOPLAM FAKTÖR VERIMLILIĞi ENDEKSI YÖNTEMLERIYLE ETKINLIK ÖLÇÜMÜ}

\section{ÖZET}

Amaç- Bu çalışmanın amacı havayolu şehir çifti pazarlarının etkinlik derecelerinin ortaya çıkarılmasıdır. Bu kapsamda etkinlik ölçümü için bu alanda yaygın olarak kullanılan yöntemlerden veri zarflama analizi ve Malmquist Toplam Faktör Verimliliği Endeksleri kullanılmıştır.

Yöntem- 2015-2017 yılları arasında Türkiye çıkışlı destinasyonların oluşturmuş olduğu dış hat şehir çifti pazarları içerisinde taşınan yolcu sayısı bakımından en büyük 16 şehir çifti pazarı analize dâhil edilmiştir. Analiz kapsamında çıktı değişkeni olarak taşınan yolcu sayısı ve doluluk oranı; girdi değişkenleri olarak ise arz edilen koltuk sayısı, ilgili hatta gerçekleştirilen uçuş sayısı gibi değişkenler kullanılmıştır. Bulgular- Veri zarflama analizinin sonuçlarına göre Atina, New York, Berlin ve Tahran hatlarının etkin olduğu ve diğerlerinin etkinlik sınırına ulaşamadığı görülmektedir.

Sonuç- Toplam faktör verimliliği endeksi sonuçlarına göre ise Tel Aviv, Frankfurt ve Stuttgart hatlarında THY'nin etkinliğini artırdığı görülmektedir. Bu çalışmanın sonucunda elde edilen bulguların havayolu sektöründeki paydaşlara yol göstereceği düşünülmektedir.

Anahtar Kelimeler: Veri zarflama analizi, toplam faktör verimliliği indeksi, etkinlik ölçümü, şehir çifti pazarları, havayolu işletmeleri. JEL Kodları: C80, L91, L93 


\section{GiRiş}

Havayolu taşımacılığı endüstrisi sunmuş olduğu hızlı yer değiştirme hizmeti nedeniyle kullanııılarına zaman ve yer faydası sağlamaktadır. Ayrıca gelişmişlik düzeyinin artmasıyla beraber sivil hava taşımacilığı yolcu ve kargo taşımada en etkili yol olmuştur (Shao ve Sun, 2016: 67). İlk zamanlar devlet kontrolünde sağlanan söz konusu hizmet ABD'de başlayan serbestleşme hareketleri doğrultusunda dünya geneline dalga dalga yayılmış ve ticari havayolu taşımacılı̆̆ havayolları tarafından serbestçe yapılabilir hale gelmiştir. Ülkemiz genelinde de önceleri ekonomik düzenlemeler açısından oldukça sıkı olan havayolu taşımacılığı belirli adımların ardından -halen ufak tefek bazı kısıllar olsa dagünümüzdeki liberal haline evrilmiştir.

Ülkemizdeki rakamlar incelendiğinde 1980 yılında yaklaşık 1,8 milyon olan dış hat yolcu sayısı 1983 serbestleşmesinin ardından 1990'lara gelindiğinde 8,2 milyon olarak gerçekleşmiş; 2003 iç hat serbestleşmesinin ardından ise 2010 yilında 52,1 milyon olmuştur (Bakırcı, 2012: 350). Ayrıca iç ve dış hatlarda faaliyet gösteren havayolu işletmelerinin sayısı da artmış ve gerek iç hatlarda gerekse dış hatlarda uçulan destinasyon sayısı açısından önceki yıllara göre büyük artışlar gerçekleşmiştir (Yaşar ve Gerede, 2018: 177). Endüstrinin tüm bileşenleri açısından artışların gözlemlendiği bu sektörde akıllara yapılan işin bir diğer ifade ile havayolu taşımacılığı hizmetinin etkin bir şekilde gerçekleştirilip gerçekleştirilmediği sorusu gelmektedir. Öyle ki söz konusu artışlar var olan kapasitenin kullanım dereceleri hakkında paydaşlara tam bir bilgi vermemektedir. Taşınan yolcu sayıları çok kısıtlı bir kapasite ile gerçeklemiş olabileceği gibi çok fazla kapasite kullanılarak da gerçeklemiş olabilir. Bu noktada havayolu işletmelerinin etkinlik derecelerinin değerlendirmeleri gereği karşımıza çıkmaktadır.

Bu çalışmanın amacı havayolu işletmelerinin etkinlik derecelerinin hat bazında değerlendirilmesidir. Bu kapsamda Türk Hava Yolları (THY)'nin 2015-2017 dönemini kapsayan ve yolcu sayısı bakımından en büyük 16 hattı karar verme birimi olarak seçilmiş ve söz konusu hatların etkinlik dereceleri Veri Zarflama Analizi ve Malmquist Toplam Faktör Verimliliği Endeksi ile belirlenmiştir.

\section{LITERATÜR INCELEMESI}

Alan yazında havayolu işletmelerinin etkinlik değerlemelerinin yapıldığı birçok çalışmaya rastlamak mümkündür. Bunlardan bir kısmı havayolu işletmelerinin bir bütün olarak etkinliği üzerinde durmuş; bazıları ise havayolu işletmelerinin faaliyet gösterdiği hatlar üzerinde etkinlik değerlendirmesi yapmıştır. Bir diğer ifade ile karar verme birimleri bazı çalışmalarda havayolu işletmelerinin kendisi olmuş, bazılarında ise faaliyet gösterilen uçuş hatları olmuştur.

Karar verme birimi olarak havayolu işletmesinin kendisinin seçildiği çalışmalardan Barros ve Peypoch (2009) Avrupalı taşıyıcıların operasyonel performansını değerlendirmiştir. Araştırma kapsamında içlerinde Türk Hava Yollarının da bulunduğu 27 havayolu işletmesinin 2000-2005 yılları arasındaki etkinlik değerleri Veri Zarflama Analizi (VZA) ile belirlenmiş ve ardından etkinliğin öncülleri olarak karşımıza çıkan bazı değişkenler regresyon analizi ile belirlemiştir. Havayolu işletmelerinde etkinliğin belirlendiği bir diğer çalışma ise Jain ve Natarajan (2015) tarafından Hindistan'daki havayolu işletmeleri üzerinde gerçekleştirlmiştir. Yazarlar VZA ile 2006-2010 yılları arasında 2 girdi (Toplam Arz Edilen Ton-Km ve İşletim Maliyetleri) ve 2 çıktı (Ücretli Yolcu-Km ve Yolcu Dışı Gelirler) kullanarak analizleri gerçekleştirmişlerdir. Yapılan analizler sonucunda düşük maliyetli havayolu işletmelerinin geleneksel havayolu işletmelerine göre daha etkin ve havayolu işletmelerinin büyüklüklerinin etkinlik üzerinde etkili olduğu bulguları elde edilmiştir. Barbot ve arkadaşları (2008) ise farklı bölgelerden 49 havayolu işletmesini karar verme birimi olarak ele almış ve söz konusu havayolu işletmelerinin etkinlik derecelerini VZA ve Toplam Faktör Verimliliği (TFV) ile değerlendirmişlerdir. Araştırma sonucunda düşük maliyetli taşıyıııların geleneksel taşıyııılara göre daha etkin olduğunu, etkinlik değerlerinin coğrafi bölgelere göre farklılık gösterdiği gibi bulgulara ulaşılmışır. Arjomandi ve Seufert (2014) ise yapılan diğer çalışmalardan farklı olarak havayolu işletmelerinin teknik ve çevresel performansını değerlendirmişlerdir. 2007-2010 dönemini kapsayan çalışma kapsamında 6 farklı bölgeden içerisinde hem düşük maliyetli hem de geleneksel havayolu işletmelerinin bulunduğu 48 havayolu VZA ile değerlendirilmiştir. Araştırma sonucunda teknik olarak en etkin havayolu işletmeleri Çin ve Kuzey Asya ülkelerindeki havayollarıyken; çevresel etkinlik düzeyi en yüksek olanlar Avrupalı taşıyııılar olarak karşımıza çıkmaktadır. Farklı bölgelerden 11 havayolu işletmesini çalışma kapsamına alan Asker (2017) havayolu işletmelerinin etkinlik olma durumlarını incelemiş ve CCR modeline göre 7, BCC modeline göre ise 8 havayolu işletmesinin etkin olduğu sonucuna ulaşmışır.

Karar verme birimi olarak hatların seçilmiş olduğu çalışmalara bakıldığında Chiou ve Chen (2006)'in Tayvan'daki yerel bir taşıyıcının faaliyet gösterdiği 15 uçuş hattında yapmış olduğu çalışmasında VZA kullanılmıştır. Analiz sonucunda 3 girdi değişkeni ile iki üretim değișkeni ve 3 hizmet değişkeni regresyon analizi için kullanılmış ve bulgular 10 hattın görece maliyet etkin, 4 hattın ise hizmet etkin hatlar olduğunu ortaya çıkarmıştır. Shao ve Sun (2016) Çin'deki 477 uçuş hattı üzerinde ağ VZA ile yaptıkları çalışmalarında yük taşıma etkinliğinin yolcu taşıma etkinliğinden düşük olduğu ve birçok uçuş hattına sahip havaalanlarının yüksek etkinlik değerlerine sahip olduğu sonuçlarına ulaşmışlardır.

\section{VERI VE YÖNTEM}

Veri zarflama analizi (VZA), ilk olarak Charnes, Cooper ve Rhodes (1978) tarafından ürettikleri mal veya hizmet açısından birbirlerine benzer ekonomik karar verme birimlerinin göreli etkinliklerinin ölçülmesi amacı ile geliştirilmiş olan parametrik olmayan bir yöntemdir. VZA, statik bir analiz şekli olup, tek bir dönemde karar birimlerinin verilerini kullanarak bir yatay kesit analizi yapar (Kula, Kandemir ve Özdemir, 2009: 191).

Analizin temelinde benzer türden karar verme birimlerinin üretim etkinliklerinin değerlendirilmesi yer almaktadır. Burada benzer türden olarak ifade edilen durum, karar verme birimlerinin hedefe yönelik benzer işlevler göstermesi, aynı pazar şartlarında yer alması ve birimlerin verimliliklerini nitelendiren etmenlerin aynı olmasıdır.

VZA'nın iki temel modeli bulunmaktadır. Bunlar Charnes-Cooper-Rhodes Modeli (CCR) Modeli ve Banker-Charnes-Cooper Modeli (BCC)'dir. CCR modeli girdiye yönelik olup, belirli bir çıktı bileşimi için en uygun girdi bileşimini araştıır. BCC modeli ise çıktıya yönelik olup, belirli bir girdi bileşiminden ne kadar çok çıktı bileşiminin sağlanabileceğini araştııır (Akyüz, Yıldız ve Kaya, 2013: 118). 
CCR-VZA modelinin Ölçeğe Göre Sabit Getiri (ÖGSG) varsayımı altında doğrusal programlama mantığı ile gösterimi aşağıdaki gibidir.

Amaç fonksiyonu:

ENB $\theta_{k}=\sum_{r=1}^{s} u_{r} y_{r k}$

KIsıtlar:

$\sum_{r=1}^{s} u_{r} y_{r j}-\sum_{i=1}^{m} v_{i} x_{i j} \leq 0 \quad j=1,2, \ldots, n$

$\sum_{i=1}^{m} v_{i} x_{i 0}=1$

$v_{i} \geq 0$

$i=1,2, \ldots, m$

$u_{r} \geq 0$

$r=1,2, \ldots, s$

$x_{i j}:$ j. karar birimi tarafından kullanılan i. girdi miktarı

$\mathrm{y}_{\mathrm{rj}}$ : j. karar birimi tarafından üretilen r. çıktı miktarı

$\mathrm{x}_{\mathrm{i}}$ : Etkinliği araştııılan karar biriminin kullandığı i. girdi miktarı

$\mathrm{y}_{\mathrm{j}}$ : Etkinliği araştırılan karar biriminin ürettiği j. çıktı miktarı

$\mathrm{v}_{\mathrm{i}}$ : Karar biriminin i. girdiye verdiği ağırlık

$u_{r}:$ Karar biriminin r. çıktıya verdiği ağırlık

Gerek girdi odakıı gerekse çıktı odaklı olsun, eğer bir karar verici karar noktalarını etkinliklerine CCR yöntemiyle karar veriyorsa modelin bütün karar noktaları için uygulaması gerekir. Kurulan bu model bütün karar noktaları için çözüldüğünde ise her bir karar noktası için toplam etkinlik ölçütleri meydana gelmektedir.

Malmquist toplam faktör verimliliği endeksi ise panel veri kullanılarak üretkenliğin zaman boyutunda gelişimini ölçmek ve nedenlerini incelemek amacıyla kullanılan bir yöntemdir. Malmquist Toplam Faktör Verimliliği (MTFV) endeksi, ortak teknolojiyi göre her bir veri noktasının farklarının oranlarını hesaplayarak, iki veri noktası arasındaki toplam faktör verimliliğindeki değişmeyi ölçer. Bu ölçüm için uzaklık fonksiyonu kullanır (Kula, Kandemir, Özdemir, 2009: 193). Uzaklık fonksiyonu aşağıda yer almaktadır:

$D_{0}^{S}(x, y)=\min \{\delta:(y / \delta) \epsilon S\}$

Uzaklık fonksiyonu çıktıya göre olup, x ile üretilebilecek y'lerin kümesini S ile göstermektedir.

MTFV değişimi indeksi ÖGSG varsayımıyla aşağıdaki notasyon ile ifade edilmektedir (Fare ve diğerleri, 1994: 69):

$M_{0}\left(x^{t+1}, y^{t+1}, x^{t}, y^{t}\right)=\sqrt{\left(\frac{D_{0}^{t}\left(x^{t+1}, y^{t+1}\right)}{D_{0}^{t}\left(x^{t}, y^{t}\right)}\right)\left(\frac{D_{0}^{t+1}\left(x^{t+1}, y^{t+1}\right)}{D_{0}^{t+1}\left(x^{t}, y^{t}\right)}\right)}$

MTFV değişimi endeksinin hesaplanmasına yönelik yukarıda verilen notasyon ile etkinlik değişimi ve teknolojik değişim açıklanmaktadır. Etkinlik değişimi ise ölçeğe göre değişken getiri varsayımı altında saf teknik etkinlik değişimi ve ölçek etkinlik değişiminin çarpımına eşit olmaktadır.

Bu çalışmada THY'nin 2015-2017 yılları arasına ait pazar verileri Uluslararası Sivil Havacılık Organizasyon (ICAO) tarafından sağlanan veritabanından elde edilmiştir. Türkiye çıkışı destinasyonların oluşturmuş olduğu dış hat şehir çifti pazarları içerisinde taşınan yolcu sayısı bakımından en büyük 16 şehir çifti pazarı analize dâhil edilmiştir. Pazarların etkinliklerinin değerlendirilmesine yönelik yıl bazı olarak VZA analizi uygulanmıştır. 3 yıllık verilerin değişimine yönelik ise MTFV değişim indeksine bakılmıştır.

\section{BULGULAR}

Veri zarflama analizinin çıktı odaklı CCR ve BCC modeline göre yapılan etkinlik ölçümü sonucunda Türk Hava Yolları işletmesinin 2015-2017 yılları arasındaki etkinlik ölçümü gerçekleştirilmiş̧ir. Etkinlik değişimin ortaya konulması amacı ile Malmquist Toplam Faktör verimliliği endeksi kullanılmıştır.

Tablo 1: Analize Dâhil Olan Hatların Çıktı Odaklı CCR ve BCC Modeli İle Etkinlik Değerleri (2015-2017)

\begin{tabular}{|l|l|l|l|l|l|l|l|l|l|}
\hline \multirow{2}{*}{$\begin{array}{l}\text { Hatlar } \\
\text { İstanbul'dan }\end{array}$} & \multicolumn{3}{l|}{ Çıktı Odaklı CCR Modeli } & \multicolumn{2}{l|}{ Çıktı Odaklı BCC modeli } & \multicolumn{2}{l|}{ Ölçek Etkinliği } \\
\cline { 2 - 10 } & $\mathbf{2 0 1 5}$ & $\mathbf{2 0 1 6}$ & $\mathbf{2 0 1 7}$ & $\mathbf{2 0 1 5}$ & $\mathbf{2 0 1 6}$ & $\mathbf{2 0 1 7}$ & $\mathbf{2 0 1 5}$ & $\mathbf{2 0 1 6}$ & $\mathbf{2 0 1 7}$ \\
\hline Londra (UK) & 0.915 & 0.907 & 0.943 & $\mathbf{1 . 0 0 0}$ & $\mathbf{1 . 0 0 0}$ & $\mathbf{1 . 0 0 0}$ & 0.915 & 0.907 \\
\hline Tel avıv (İsrail) & 0.872 & 0.876 & 0.877 & 0.938 & 0.954 & 0.928 & 0.930 & 0.918 \\
\hline Ercan (Kıbrıs) & $\mathbf{1 . 0 0 0}$ & 0.966 & 0.941 & $\mathbf{1 . 0 0 0}$ & 0.994 & 0.974 & $\mathbf{1 . 0 0 0}$ & 0.971 & 0.945 \\
\hline Paris (Fransa) & 0.912 & 0.933 & 0.929 & 0.935 & 0.977 & 0.961 & 0.976 & 0.955 \\
\hline Amsterdam (Hollanda) & 0.904 & 0.889 & 0.928 & 0.904 & 0.913 & 0.949 & 0.999 & 0.974 \\
\hline Frankfurt (Almanya) & 0.896 & 0.919 & 0.950 & 0.901 & 0.953 & 0.968 & 0.994 & 0.965 & 0.967 \\
\hline Tahran (İran) & 0.956 & 0.877 & 0.883 & 0.956 & 0.905 & 0.904 & $\mathbf{1 . 0 0 0}$ & 0.970 \\
\hline Dusseldorf (Almanya) & 0.959 & 0.931 & 0.905 & 0.96 & 0.954 & 0.922 & 0.999 & 0.975 \\
\hline Berlın (Almanya) & 0.942 & 0.876 & 0.918 & 0.942 & 0.901 & 0.929 & $\mathbf{1 . 0 0 0}$ & 0.972 & 0.971 \\
\hline New york (ABD) & $\mathbf{1 . 0 0 0}$ & $\mathbf{1 . 0 0 0}$ & $\mathbf{1 . 0 0 0}$ & $\mathbf{1 . 0 0 0}$ & $\mathbf{1 . 0 0 0}$ & $\mathbf{1 . 0 0 0}$ & $\mathbf{1 . 0 0 0}$ & $\mathbf{1 . 0 0 0}$ & $\mathbf{1 . 0 0 0}$ \\
\hline Münih (Almanya) & 0.956 & 0.850 & 0.903 & 0.965 & 0.871 & 0.908 & 0.991 & 0.976 \\
\hline
\end{tabular}




\begin{tabular}{|l|l|l|l|l|l|l|l|l|l|}
\hline Viyana (Avusturya) & 0.865 & 0.851 & 0.846 & 0.866 & 0.854 & 0.851 & 0.999 & 0.998 & 0.993 \\
\hline Stuttgart (Almanya) & 0.922 & 0.919 & 0.949 & $\mathbf{1 . 0 0 0}$ & 0.924 & 0.951 & 0.922 & 0.999 \\
\hline Brüksel (Belçika) & 0.886 & 0.919 & 0.878 & 0.888 & 0.925 & 0.878 & 0.998 & 0.999 \\
\hline Atina (Yunanistan) & 0.886 & $\mathbf{1 . 0 0 0}$ & $\mathbf{1 . 0 0 0}$ & 0.887 & $\mathbf{1 . 0 0 0}$ & $\mathbf{1 . 0 0 0}$ & 0.999 & $\mathbf{1 . 0 0 0}$ & $\mathbf{1 . 0 0 0}$ \\
\hline Milan (İtalya) & 0.857 & 0.811 & 0.756 & 0.858 & 0.816 & 0.760 & 0.999 & 0.998 & 0.994 \\
\hline
\end{tabular}

Tablo 1'e göre 2015 yılında veri zarflama analizinin çıktı odaklı CCR ve BCC modellerine göre yapılan etkinlik ölçümü sonucunda Türk Hava Yolları İşletmesinin faaliyet göstermiş olduğu ilgili hatlar içerisinde sadece Kıbrıs'a ve New York'a yapmış olduğu uçuşlarda belirli bir etkinliğe ulaştığı söylenebilmektedir. Diğer hatlarda ise etkinlik sınırına ulaşılamamıştır. Ancak İran ve Berlin uçuşlarında ölçek açısından etkinlik sınırına ulaşabilmiştir. VZA ile 2016 yılında yapılan etkinlik ölçümüne göre sadece New York ve Atina Hatlarının etkin çıktığı diğer hatların ise etkin çıkmadıkları görülmüştür. Yalnız 2015 yılında olduğu gibi Londra hattının çıktı odaklı BCC modeline göre etkin çıktığı tespit edilmiştir. 2017 yılında VZA ile yapılan etkinlik ölçümünde THY'nin sadece Atina ve New York hatlarında etkin olduğu diğer hatlarda ise etkinlik değerinin altında kaldığı görülmüştür. Çıktı odaklı BCC modeline göre ise Londra hattının etkin çıktığı görülmüştür.

Tablo 2: Malmquist TFV Endeksi (2016-2015)

\begin{tabular}{|c|c|c|c|c|c|c|c|c|c|c|c|c|c|c|c|}
\hline \multirow{2}{*}{$\begin{array}{l}\text { Hatlar } \\
\text { İstanbul'dan }\end{array}$} & \multicolumn{3}{|c|}{ Etkinlik değişimi } & \multicolumn{3}{|c|}{ Teknolojik Değişim } & \multicolumn{3}{|c|}{ Saf etkinlik değişimi } & \multicolumn{3}{|c|}{$\begin{array}{l}\text { Ölçek Etkinliği } \\
\text { Değişimi }\end{array}$} & \multicolumn{3}{|c|}{$\begin{array}{c}\text { Toplam faktör } \\
\text { verimliliğindeki } \\
\text { değişim }\end{array}$} \\
\hline & $\begin{array}{l}2016 \\
/ 2015 \\
\end{array}$ & $\begin{array}{l}2017 / \\
2016 \\
\end{array}$ & $\begin{array}{l}2017 / \\
2015 \\
\end{array}$ & $\begin{array}{l}2016 \\
/ 2015 \\
\end{array}$ & $\begin{array}{l}2017 / \\
2016 \\
\end{array}$ & $\begin{array}{l}2017 / \\
2015 \\
\end{array}$ & $\begin{array}{l}2016 \\
/ 2015 \\
\end{array}$ & $\begin{array}{l}2017 / \\
2016 \\
\end{array}$ & $\begin{array}{l}2017 / \\
2015 \\
\end{array}$ & $\begin{array}{l}2016 \\
/ 2015 \\
\end{array}$ & $\begin{array}{l}2017 / \\
2016 \\
\end{array}$ & $\begin{array}{l}2017 / \\
2015 \\
\end{array}$ & $\begin{array}{l}2016 \\
/ 2015 \\
\end{array}$ & $\begin{array}{l}2017 / \\
2016\end{array}$ & $\begin{array}{l}2017 / \\
2015 \\
\end{array}$ \\
\hline Londra (UK) & 0.991 & 1.041 & 1.015 & 0.982 & 1.022 & 1.002 & 1.000 & 1.000 & 1.000 & 0.991 & 1.041 & 1.015 & 0.973 & 1.063 & 1.017 \\
\hline Tel avıv (İsrail) & 1.004 & 1.002 & 1.003 & 0.982 & 1.022 & 1.002 & 1.021 & 0.974 & 0.997 & 0.984 & 1.029 & 1.006 & 0.986 & 1.024 & 1.005 \\
\hline Ercan (Kıbrıs) & 0.966 & 0.974 & 0.970 & 0.889 & 1.022 & 0.953 & 0.993 & 0.979 & 0.986 & 0.972 & 0.995 & 0.984 & 0.859 & 0.995 & 0.925 \\
\hline Paris (Fransa) & 1.023 & 0.996 & 1.009 & 0.982 & 1.022 & 1.002 & 1.055 & 0.984 & 1.019 & 0.969 & 1.012 & 0.991 & 1.004 & 1.018 & 1.011 \\
\hline $\begin{array}{l}\text { Amsterdam } \\
\text { (Hollanda) }\end{array}$ & 0.983 & 1.044 & 1.013 & 0.931 & 1.022 & 0.976 & 0.967 & 1.053 & 1.009 & 1.017 & 0.992 & 1.004 & 0.916 & 1.067 & 0.989 \\
\hline $\begin{array}{l}\text { Frankfurt } \\
\text { (Almanya) }\end{array}$ & 1.026 & 1.033 & 1.030 & 0.963 & 1.022 & 0.992 & 1.048 & 1.021 & 1.034 & 0.979 & 1.012 & 0.995 & 0.988 & 1.056 & 1.021 \\
\hline Tahran (İran) & 0.918 & 1.006 & 0.961 & 0.923 & 1.022 & 0.971 & 0.919 & 1.009 & 0.963 & 0.998 & 0.997 & 0.998 & 0.847 & 1.028 & 0.933 \\
\hline $\begin{array}{l}\text { Dusseldorf } \\
\text { (Almanya) }\end{array}$ & 0.970 & 0.973 & 0.971 & 0.94 & 1.022 & 0.980 & 0.982 & 0.967 & 0.975 & 0.988 & 1.006 & 0.997 & 0.912 & 0.994 & 0.952 \\
\hline Berlın (Almanya) & 0.929 & 1.049 & 0.987 & 0.922 & 1.022 & 0.971 & 0.929 & 1.043 & 0.984 & 1.000 & 1.005 & 1.003 & 0.857 & 1.072 & 0.958 \\
\hline New york (ABD & 1.000 & 1.000 & 1.000 & 0.937 & 1.057 & 0.995 & 1.000 & 1.000 & 1.000 & 1.000 & 1.000 & 1.000 & 0.937 & 1.057 & 0.995 \\
\hline Münih (Almanya) & 0.889 & 1.062 & 0.972 & 0.894 & 1.023 & 0.956 & 0.864 & 1.079 & 0.966 & 1.029 & 0.984 & 1.006 & 0.795 & 1.086 & 0.929 \\
\hline $\begin{array}{l}\text { Viyana } \\
\text { (Avusturya) }\end{array}$ & 0.984 & 0.993 & 0.989 & 0.898 & 1.029 & 0.961 & 0.96 & 0.967 & 0.963 & 1.025 & 1.027 & 1.026 & 0.884 & 1.021 & 0.950 \\
\hline $\begin{array}{l}\text { Stuttgart } \\
\text { (Almanya) }\end{array}$ & 1.001 & 1.027 & 1.014 & 0.860 & 1.075 & 0.961 & 0.954 & 1.020 & 0.987 & 1.049 & 1.007 & 1.028 & 0.861 & 1.104 & 0.975 \\
\hline Brüksel (Belçika) & 1.043 & 0.95 & 0.995 & 0.873 & 1.075 & 0.969 & 1.006 & 0.973 & 0.99 & 1.036 & 0.976 & 1.006 & 0.911 & 1.021 & 0.964 \\
\hline $\begin{array}{l}\text { Atina } \\
\text { (Yunanistan) }\end{array}$ & 1.128 & 1.000 & 1.062 & 0.864 & 1.068 & 0.961 & 1.046 & 1.000 & 1.023 & 1.078 & 1.000 & 1.038 & 0.975 & 1.068 & 1.021 \\
\hline Milan (İtalya) & 0.950 & 0.928 & 0.939 & 0.883 & 1.055 & 0.965 & 0.931 & 0.975 & 0.953 & 1.020 & 0.952 & 0.985 & 0.838 & 0.979 & 0.906 \\
\hline
\end{tabular}

Tablo 2'ye bakıldığında THY'nin faaliyet göstermiş olduğu ilgili hatlarda 2016-2015 döneminde Tel Aviv, Paris, Frankfurt, Stuttgart, Bürüksel ve Atina hatlarında etkinliğini arttırdığı görülmektedir. Diğer hatlarda ise etkinlik değerlerinin düştüğü görülmektedir. New York hattında ise etkinlik değişiminin olmadığı tespit edilmiştir. Teknolojik değişim açısından ise tüm hatların etkinliklerinin düştüğü görülmüştür. THY'nin 2017-2016 döneminde Londra, Tel Aviv, Amsterdam, Frankfurt, Tahran, Berlin, Münih, Stuttgart hatlarında etkinlik değiş̧iminde artış olduğu diğer hatlarda ise bir azalış olduğu tespit edilmiştir. Toplam faktör verimliliği açısından ise ilgili hatların büyük bir kısmında verimlilik artışı olduğu görülmektedir. 2017-15 karşılaştırmsında THY'nin faaliyet göstermiş olduğu ilgili hatlarda Londra, Tel Aviv, Paris, Amsterdam, Frankfurt, Stuttgart ve Atina Hatlarında etkinlik değişiminin pozitif yönde olduğu diğer hatlarda ise etkinlik değişiminin negatif yönde olduğu görülmüştür. New York hattında 2015 ve 2016 yıllarında olduğu gibi etkinlik değişiminin olmadığı tespit edilmiştir.

\section{SONUÇ}

Bu çalışmada, Türk Hava Yolları işletmesinin faaliyet göstermiş olduğu en yoğun 16 hattın 2015-2017 yılları arasındaki etkinliği veri zarflama analizinin çıktı odaklı CCR ve BCC modellerine göre ölçülmüştür. Etkinlik ve verimlilik değişiminin ortaya konması amacı ile malmquist toplam faktör verimliliği endeksi kullanılmıştır. Analiz sonucunda THY'nin faaliyet göstermiş olduğu ilgili hatların büyük bir kısmının etkin olmadığı görülmüştür. Ancak toplam faktör verimliliği açısından ilgili hatlardaki etkinlik durumunun pozitif yönde artı̧̧ gösterdiği tespit edilmiştir. Ancak bu durumun yine de yeterli olmadığı düşünülmektedir. İlerleyen çalışmalarda hat sayısı, girdi ve çıktı sayısı arttırılarak daha ayrıntılı sonuçlar elde edilebileceği düşünülmektedir. 


\section{KAYNAKLAR}

Akyüz, Y., Yıldız, F., Kaya, Z. (2013). Veri Zarflama Analizi (VZA) Malmquist Endeksi ile toplam faktör verimlilik ölçümü BisT’te işlem gören mevduat bankaları üzerine bir uygulama. Atatürk Üniversitesi İktisadi ve İdari Bilimler Dergisi, 27(4), 110-130.

Arjomandi, A., Seufert, J. H. (2014). An evaluation of the world's major airlines' technical and environmental performance. Economic Modelling, 41, 133-144.

Asker, V. (2017). Seçilmiş havayolu işletmelerinde Veri Zarflama Analizi ile etkinlik ölçümü. V.Anadolu International Congress in Economics.

Bakırcı, M. (2012). Ulaşım coğrafyası açısından Türkiye'de havayolu ulaşımının tarihsel gelişimi ve mevcut yapısı. Marmara Coğrafya Dergisi, $25,340-377$.

Barbot, C., Costa, Á., Sochirca, E. (2008). Airlines performance in the new market context: a comparative productivity and efficiency analysis. Journal of Air Transport Management, 14(5), 270-274.

Barros, C. P., Peypoch, N. (2009). An evaluation of European airlines' operational performance. International Journal of Production Economics, 122(2), 525-533.

Charnes, A., Cooper, W. W., Rhodes, E. (1978). Measuring the efficiency of decision making units. European journal of operational research, 2(6), 429-444.

Chiou, Y. C., Chen, Y. H. (2006). Route-based performance evaluation of Taiwanese domestic airlines using data envelopment analysis. Transportation Research Part E: Logistics and Transportation Review, 42(2), 116-127.

Fare, R., Grosskopf, S., Norris, M., Zhang Z., (1994). Productivity growth, technical progress, and efficiency change in industrialized countries. The American Economic Review, 84 (1): 66-83.

Jain, R. K., Natarajan, R. (2015). A DEA study of airlines in India. Asia Pacific Management Review, 20(4), $285-292$.

Kula, V., Kandemir, T., Özdemir, L. (2009). VZA Malmquist toplam faktör verimlilik ölçüsü: IMKB'ye koteli çimento şirketleri üzerine bir araştırma. Sosyal ve Ekonomik Araştırmalar Dergisi, 9 (17), 186-202.

Shao, Y., Sun, C. (2016). Performance evaluation of China's air routes based on network data envelopment analysis approach. Journal of Air Transport Management, 55, 67-75.

Yaşar, M., Gerede, E. (2018). Türkiye havayolu iç hat şehir çiftlerindeki pazar yapılarının piyasa yoğunlaşması ölçütleri ile belirlenmesi. Yonetim ve Ekonomi, 25(1), 171-197. 